\title{
Design of Low Flow Undershot Type Water Turbine
}

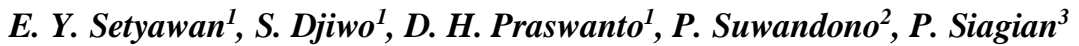 \\ ${ }^{I}$ Mechanical Engineering, Faculty of Engineering, National Institute of Technology Malang, Jl. Bendungan Sigura-gura \\ No.2 Malang 65152, Indonesia \\ ${ }^{2}$ Mechanical Engineering Department, Universitas Widyagama Malang, Jl. Taman Borobudur, Malang, Indonesia \\ ${ }^{3}$ Mechanical Engineering, Universitas HKBP Nommensen, Medan, Indonesia
}

Email:Djoko@lecturer.itn.ac.id

\begin{abstract}
Many water sources around us which have kinetic energy to run waterwheels are not optimally utilized. This energy can be converted into an energy source that can produce electricity. Therefore this study produced a design of a waterwheel that could be used in low-flow rivers to produce electricity by adding generators. Waterwheel modeling using Ansys is calculated based on flow assumptions. Modeling using this system provides advantages in the form of computational power efficiency, the stability of numerical calculations and the accuracy of the resulting solutions. Numerical analysis of the waterwheel is assumed that the waterwheel is half floating on the surface of the water. As stated in the limitation of the problem that the incoming water flowing at a speed of $5 \mathrm{~m} / \mathrm{s}$ from the flow moves the wheel. The flow rate of water that hit the blade on the waterwheel causes the waterwheel to rotate which is pressured by the flow of water with a number of 12 blades. With a relatively simple design, the waterwheel produces a wheel rotation I of $91 \mathrm{Rpm}$ and II of 78 Rpm, with a torque of $39.2 \mathrm{~N}$ by using some analysis of this design can be applied to river flow with low flow velocity. The relatively simple design makes it easy to be produced and maintenance. River flow used is in the Malang District with a flow velocity of $1 \mathrm{~m} / \mathrm{s}$ gets a power of $1128 \mathrm{~W}$ on waterwheel I while on waterwheel II gets a power of $967 \mathrm{~W}$.
\end{abstract}

Keywords: Water Turbine, Undershot, Low Flow

Paper type Research paper

\section{INTRODUCTION}

Based on the problem of the electricity crisis and the increasing energy needs, the energy potential of this river flow must be utilized to the maximum extent possible. One of them is by designing hydroelectric power plants $[1,2]$ to meet electricity needs by utilizing small water sources [3,4].

The water sources are expected to be able to reduce costs, so that it no longer requires large costs but with a small cost of producing maximum performance, by using existing materials around us the efficiency is quite low reaching $24 \%$ [5] because it is done traditionally. If you want to increase efficiency by up to $60 \%$, you can make a classic vertical type water wheel $[6,7]$ by working the change in the potential energy present in the flow of water into mechanical energy by the wheel. Second is the change in mechanical energy produced will be used to turn a generator that will produce electrical energy.

Prasad et al. [8] compared the axial efficiency of flow turbines coming through experimental and CFD analysis with three different guide vane angles. Jain and Saini [9] have estimated the performance and efficiency of Francis runners in 4 different operations of the propeller guide points using CFD and to validate the same as testing the model. Kim et al. [10] predicted the tubular performance of a hydro turbine type for aperture opening guide variable and the influence of pressure, tangential and axial investigated velocity distribution on turbine performance using CFD [11].

A research has been done by Hung regarding the analysis of the performance and field of waterwheels by utilizing tidal energy using six and nine blades produce good efficiency. From the results of the experiment, the more blades used the greater the torque produced, but the depth of the upstream and downstream of the turbine also increased significantly in the same way and the same flow [12].

The use of waterwheels has been done for a long time by utilizing the energy of running water. Energy that is owned by water can be utilized and used in the form of mechanical energy to produce electricity. Average waterwheels are used on a small scale so that precise calculations are needed in order to get maximum results. Waterwheels are expected to evolve into an efficient tool that uses design and analysis using several important parameters [13].

Therefore, a waterwheel design that is expected to be able to meet the small scale power consumption is done. This waterwheel is especially used for household consumers in areas far from cities that have good efficiency. For this reason, the power plant designed is the one that utilizes the energy of river water flow that has a flow capacity that is not too large, which is commonly found in the regions. In line with the explanation above, the purpose of this paper is to study the characteristics of undershot type waterwheels using twelve fruit blades. 


\section{METHOD}

This research method uses analysis by collecting various references related to waterwheels. Next, make a numerical design of a waterwheel simulation using Ansys Student Version 19.1. The waterwheel planning is based on theory and several approaches to get better efficiency. The flat plate theory approach that is placed in the flow of water used to rotate the waterwheel consisting of 12 blades with axles of $19 \mathrm{~mm}$, by using the equation as below:

$$
S=L \times(D / 2) x(1-\cos \theta / \sin \alpha)
$$

$\mathrm{S}$ is a submerged blade surface where $\mathrm{L}$ is the width of the water wheel $(\mathrm{m})$; $\mathrm{D}$ is the diameter of the water wheel (m) and $\alpha$ is the tilt angle.

$$
P=C p x(\rho / 2) \times v r^{2} \times S
$$

$\mathrm{P}$ is the lifting force; where Cp lift coefficient; $\rho$ is the density $(\mathrm{kg} / \mathrm{m} 3) ; \mathrm{Vr}$ is the radial velocity $(\mathrm{m} / \mathrm{s}) ; \mathrm{S}$ is the surface of the submerged blade $(\mathrm{m})$

$$
\mathrm{R}=\mathrm{Cp} \times(\rho / 2) \times v t^{2} \times S
$$

The tensile force where $\mathrm{Cp}$ is the lift coefficient $\rho$ is the density $(\mathrm{kg} / \mathrm{m} 3) ; \mathrm{Vt}$ is the tangential velocity $(\mathrm{m} / \mathrm{s}) ; \mathrm{S}$ is the surface of the submerged blade $(\mathrm{m})$.

$$
F=\sqrt{P^{2}+R^{2}}
$$

$F$ is the resultant force.

$$
\begin{aligned}
& F u=F x \cos \varepsilon \\
& \varepsilon=\arctan (C R / C P)-(a-\gamma)
\end{aligned}
$$

$F U$ is the useful force and angle, where $\gamma$ is the relative speed angle.

$$
M=F u x(D / 4) \times(1+\operatorname{Cos} \theta / \operatorname{Sin} \alpha)
$$

$\mathrm{M}$ is the useful moment, where $\theta$ is the angle between the center of the wheel and the position of the blade's maximum load.

$$
\begin{aligned}
& N u=M \times \omega=F u \times v t \\
& N m e d=K i S(N u / n)
\end{aligned}
$$

$\mathrm{Nu}$ is the instantaneous strength and average strength where $\mathrm{n}$ is the number of points calculated between zero action positions, values are usually taken between $1<\mathrm{n}<6$ and the maximum blade load position, while Ki is the active blade coefficient, for the undershot type of turbine $K i=1.6$

$$
\begin{aligned}
& \operatorname{Nmax}=(\rho / 2) x S \max \times v^{2}{ }^{3} \\
& S \max =L
\end{aligned}
$$

Nmax is the maximum strength of the flow, Smax is the maximum surface of the submerged blade and $h$ is the ratio of the submerged blade.

$$
\eta=\text { Nmed } / \text { Nmax }
$$

$\eta$ is the waterwheel efficiency; while $\omega$ is the angular speed:

$$
\omega=4 v t /[D(1+\operatorname{Cos} \theta / \operatorname{Sin} \alpha)]
$$

$n$ med is the rotation speed:

$$
\begin{aligned}
& n \text { med }=(30 / \pi n) \times S \omega j \\
& \theta=\cos -1[\{(0.5 \times D)-(B \times h)\} /(0.5 \times D)] \\
& \alpha=(90-\theta)+\theta \times(m / m+1)
\end{aligned}
$$


$m$ is a constant $1 \leq \mathrm{m} \leq 6$

To find out the Radial velocity, the equation below is used:

$$
V r=v\left(\operatorname{Vam}^{2}-2 x \operatorname{Vam} x \operatorname{Vt} x \sin a+V t^{2}\right)
$$

To determine the Tangential Speed, the equation below is used:

$$
\begin{aligned}
& V t=(\operatorname{Vam} x \sin \alpha) \times 0.5 \times[1+(\cos \theta / \sin \alpha)] \\
& \tan \gamma=(\text { Vt } x \cos a) /(\text { Vam }-V t \times \sin a)
\end{aligned}
$$
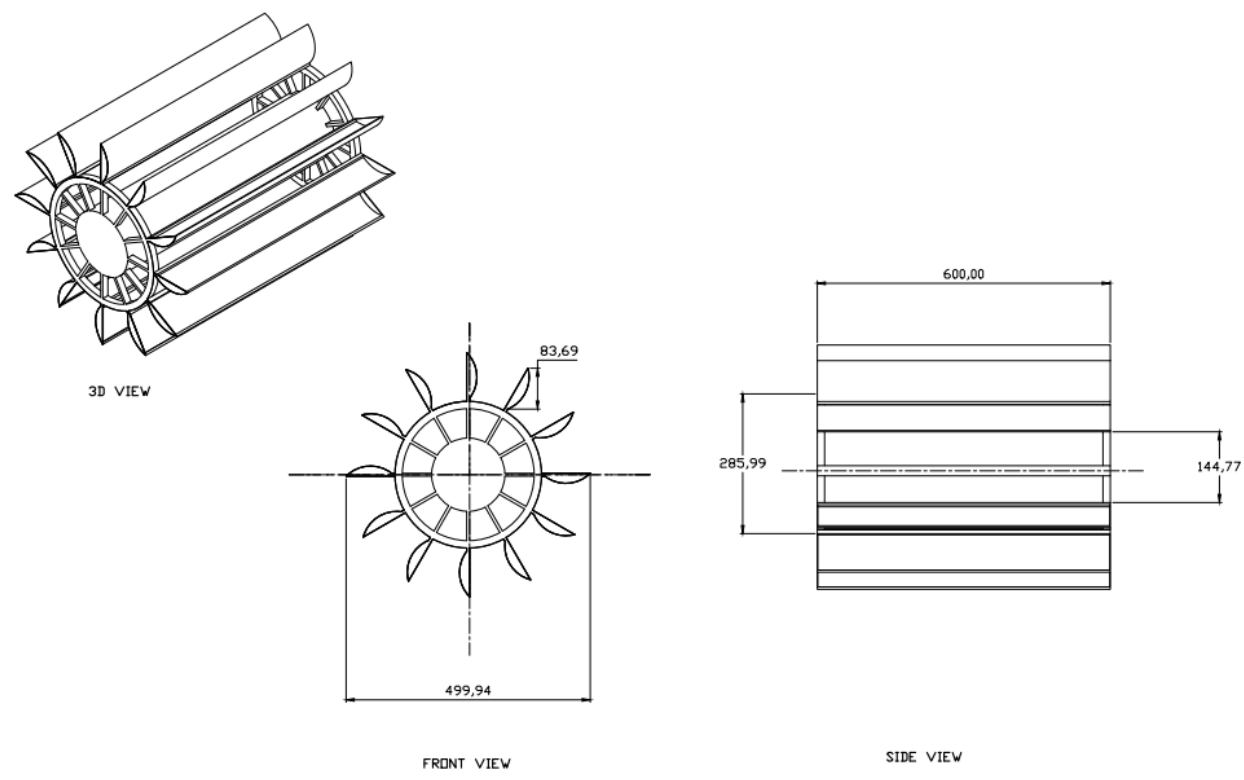

Figure 1. Design and dimensions of the waterwheel simulation area

Design and dimensions in Figure 1 above is obtained from calculations 1 to 15. In accordance with the objectives of this study, a waterwheel that was previously simulated using CFD is a numerical fluid flow approach method with the help of a computer. Next, we produce it for experimental needs by using river flow that works on low water flow. It suits the character of the river flow in the areas so that it can be applied in Indonesia which has many small islands. The design and construction of a vertical water wheel is obtained as shown in Figure 1, the dimensions of the blade length of 600 $\mathrm{mm}$ and the width of the blade of $100 \mathrm{~mm}$ with a number of 12 blades, to determine the speed of water flow before and after passing the water wheel.

\section{DISCUSSION}

\section{Initial and boundary conditions}

Waterwheel modeling using Ansys Student Version 19.1 is calculated based on flow assumptions. With an initial flow velocity of $4.85 \mathrm{~m} / \mathrm{s}$ by entering an acceleration value of gravity of $9.81 \mathrm{~m} / \mathrm{s} 2$. One of the approach models used is $\mathrm{k}$-epsilon. Modeling using this system provides advantages in the form of computational power efficiency, the stability of numerical calculations and the accuracy of the resulting solutions. By using a water-liquid fluid material, by stating that the waterwheel moves based on the flow of water by selecting "Relative to cell zone: fluid-solid" means that the speed of the wheel will be adjusted to the conditions in the water flow.

\section{Simulation results}

Numerical analysis of the waterwheel is assumed that the waterwheel is half floating on the surface of the water. As stated in the limitation of the problem that the incoming water flowing at a speed of $5 \mathrm{~m} / \mathrm{s}$ from the flow moves the wheel. The flow rate of water that hit the blade on the waterwheel causes the waterwheel to rotate as shown in Figure 2 is a waterwheel which is pressured by the flow of water with a number of 12 blades. The simulation results from the pressure distribution experienced by each waterwheel blade evenly distributed. 


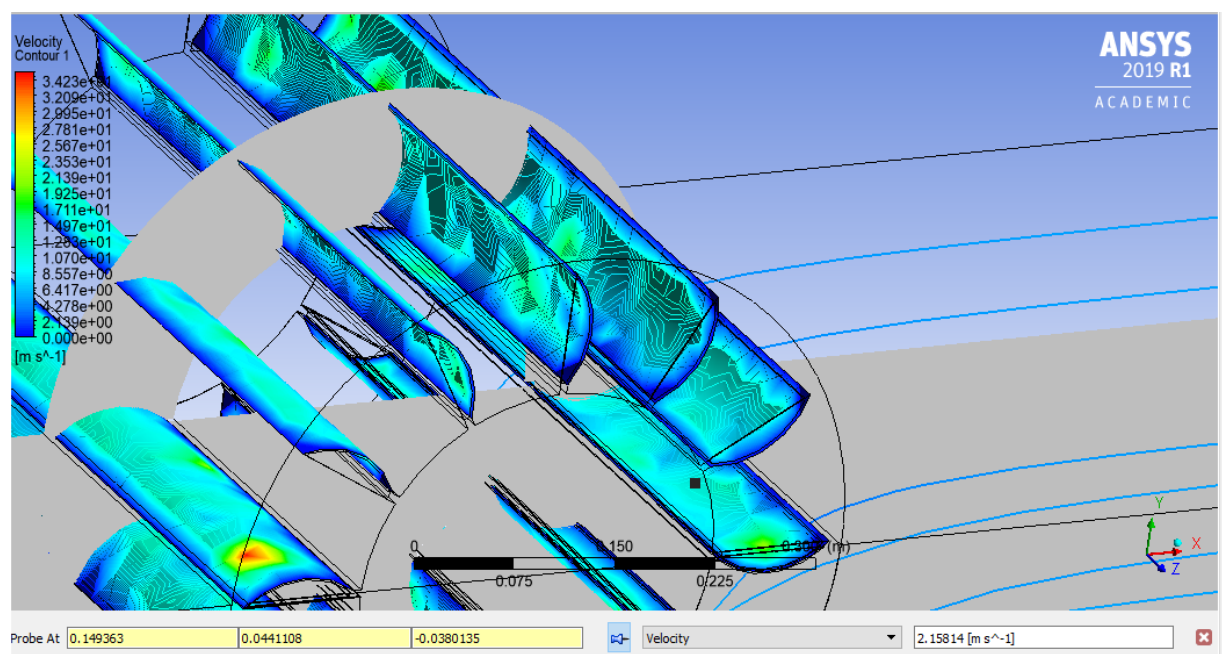

Figure 2. Speed experienced by the wheel while spinning

Figure 2. shows the results of the distribution of water flow velocity on each waterwheel blade. The red color indicates the area of the highest flow velocity at the waterwheel blade with a maximum value of $3.42 \mathrm{~m} / \mathrm{s}$, while the lowest water flow velocity on the waterwheel blade is light blue with a value of $2,158 \mathrm{~m} / \mathrm{s}$. The numerical analysis results obtained from the simulation results obtained water wheel speed of $2.19 \mathrm{~m} / \mathrm{s}$. as shown in Figure 4. Equilibrium of undershot type waterwheels.

\section{Experiment}

This experimental stage is the testing phase carried out at low river flow speeds with an average speed of $1 \mathrm{~m} / \mathrm{s}$ because at the time of testing a small water volume. By using the undershot type waterwheel by the way of working if there is a flow of running water will hit the wall of the blade located at the bottom of the waterwheel. The character of an undershot waterwheel does not have the advantage of heat. Because this type works on shallow, even streams. The selection of the waterwheel is obtained from several waterwheels including overshot, back shot, breast shot and undershot currently used, namely 2 waterwheels with different angles and forms of money as shown in Figure 3 Undershot waterwheel.

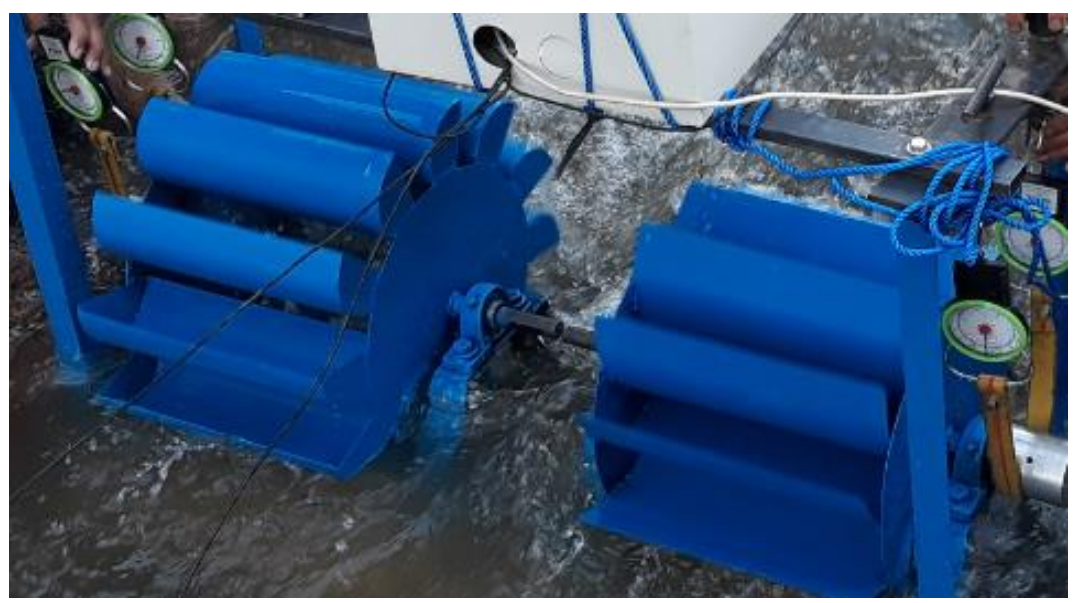

Figure 3. Undershot type waterwheel

In Figure 3 the test shows 2 undershot type waterwheels with different designs. Data was collected directly in the field, in Malang district. Retrieval of these data is combined to determine the speed of water in the river which is an average of $1 \mathrm{~m} / \mathrm{s}$. so the torque of movement on the wheel can be measured based on current by placing different masses of different weights. The mass is added until the wheel stops rotation, used to determine the torque of movement by creating an equilibrium condition at the wheel stop as shown in Figure 4. Undershot type water wheel balance. 


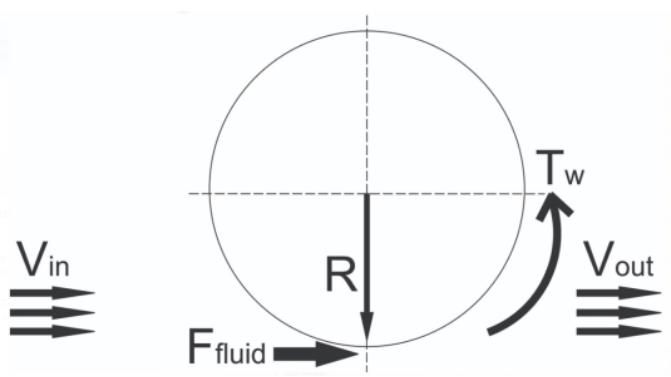

Figure 4. Equilibrium of undershot type waterwheels.

After the flow velocity and the state of equilibrium are known, the next stage is measuring the torque of 2 windmills. Torque itself is the power to rotate the waterwheel because of the flow of water, used a simple dynamometer type rope brake as shown in Figure 5 below.

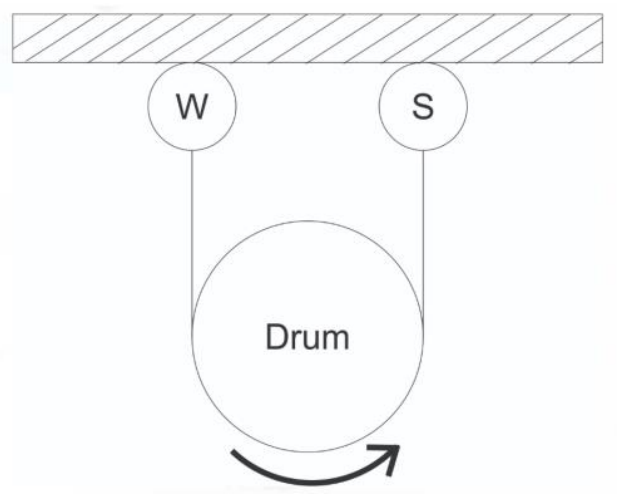

Figure 5. Rope brake dynamometer

This is one simple dynamometer consisting of two ropes wrapped around a drum whose water strength will be measured using a measuring instrument. Where the blurred side is connected by a measuring device, to find out the pull is symbolized by $\mathrm{S}$. the tight side of the shoulder bearing the dead weight is symbolized with W. so that the braking torque can be obtained.

$$
\mathrm{Tb}=(\mathrm{w}-\mathrm{s}) \mathrm{r}
$$

Where the effective drum radius is in meters $\left(r b+r\right.$ '), $R b$ is the radius of the drum $(m)$ and $R^{\prime}$ is the radius of the rope $(\mathrm{m})$. Therefore the power of the waterwheel is given like this:

$$
P b=\frac{(\mathrm{w}-\mathrm{s}) \times \mathrm{rX} 2 \pi \mathrm{N}}{60 \times 1000} k w
$$

From the equation above we get an effective voltage water wheel on the $39.2 \mathrm{~N}$ rope with a brake voltage on the first wheel of $1.2 \mathrm{KW}$, with a speed obtained of $91 \mathrm{Rpm}$. with an indication of brake power of $1128 \mathrm{~W}$ if the mechanical efficiency is $80 \%$. While on the second wheel braking voltage on the water wheel of $0.9 \mathrm{KW}$ with a speed obtained of 78 Rpm with an indication of brake power of $967 \mathrm{~W}$.

\section{CONCLUSION}

Based on the experimental research results using low flow river flow with an average speed of $1 \mathrm{~m} / \mathrm{s}$, with a spinning wheel I of $91 \mathrm{Rpm}$ and II of $78 \mathrm{Rpm}$, with a torque of $39.2 \mathrm{~N}$ by using some analysis of this design can be applied to river flow velocity low flow with a relatively simple design that is easy to make and easy to maintain. Why is there a difference between water wheel I and water wheel II because water wheel I has a higher friction factor than water wheel II, because in waterwheel II there are additional side covers.

\section{ACKNOWLEDGMENT}

We would like thank to campus National Institute of Technology Malang for funding the research and researcher from Universitas Widyagama and Universitas HKBP Nommensen. 


\section{References}

[1] Panwar NL, Kaushik SC, Surendra K. Role of renewable energy sources in environmental protection: a review. Renewable and Sustainable Energy Reviews 2011;15:1513-24.

[2] Yuksek O, Komurcu MI, Yuksel I, Kaygusuz K. The role of hydropower in meeting Turkey's electric energy demand. Energy Policy 2006;34:3093-103.

[3] Yuksel I. Hydropower in Turkey for a clean and sustainable energy future. Renewable and Sustainable Energy Reviews 2008;12:1622-40.

[4] Yukse, I "As a renewable energy hydropower for sustainable development in Turkey" Renewable and Sustainable Energy Reviews 14 (2010) 3213-3219

[5] Vashisht AK. Current status of the traditional watermills of the Himalayan region and the need of technical improvements for increasing their energy effiency. Appl Energy 2012;98:307-15.

[6] Miller G, Kauppert K. Performance characteristics of water wheels. J Hydraul Res 2004;42(5):45-60.

[7] Denny M. The effiency of overshot and undershot waterwheels. Eur J Phys 2004;25:193-202.

[8] Prasad, V, Gahlot, V K \& Krinnamachar, P "CFD approach for design optimization and validation for axial flow hydraulic turbine" Indian Journal of Engineering \& Material secince Vol. 16, August 2009,pp 229-236

[9] Jain, S, Saini,R P \& Kumar, A “CFD approach for prediction of efficiency of Francis turbine” IGHEM-2010, oct. 21-23, AHEC, IIT Roorkee, India

[10] Kim, Y T, Nam, S H, Cho, Y J, Hwang, Y, C, Choi,Y D, Nam, C D \& Lee, Y H "Tubular-Type hydro turbine performance for variable guide vane opening by CFD" The fifth international conference on fluid mechanics, Aug 15-19,2007, Shanghai, Chaina.

[1]] E.Y Setyawan, S Djiwo and T Sugiarto, Simulation Model of Fluid Flow and Temperature Distribution in Porous Media Using Cylinder Convergent and Divergent Nozzle, Internasional Journal of Technology and Sciences, 1 (2017) 1-10.

[12] M. H. Nguyen, H. Jeong, and C. Yang, "A study on flow fields and performance of water wheel turbine using experimental and numerical analyses," Sci. China Technol. Sci., vol. 61, no. 3, pp. 464-474, 2018.

[13] Denny M. “The efficiency of overshot and undershot water wheels".European journal of physics. Vol. 25, no 193-202,2014 